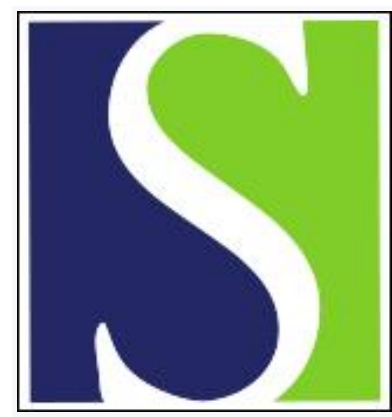

Scand J Work Environ Health 2014;40(4):411-419

https://doi.org/10.5271/sjweh.3422

Published online: 19 Mar 2014, Issue date: 01 Jul 2014

Occupational lifting during pregnancy and child's birth size in a large cohort study

by Juhl M, Larsen PS, Andersen PK, Svendsen SW, Bonde JP, Nybo Andersen A-M, Strandberg-Larsen K

We found that pregnant women who lifted many kilos per day in jobs with person-lifting (nurses, nursery assistants etc.) might be at higher risk of having a small-for-gestational-age baby. Our results lacked statistical significance, though, and we believe further investigation among these occupational groups is warranted.

Affiliation: The Research Unit Women's and Children's Health, The Juliane Marie Centre, Rigshospitalet, Dep.7821, DK - 2100 Copenhagen $\varnothing$, Denmark. metjuhl@gmail.com

Refers to the following texts of the Journal: 1987;13(5):399-403 2013;39(4):335-342

The following articles refer to this text: $2015 ; 41(2): 184-193$; 2015;41(4):397-406; 2020;46(3):259-267

Key terms: antenatal guideline; birth size; birth weight; cohort study; fetal growth; occupational lifting; offspring; pregnancy; work environment

This article in PubMed: www.ncbi.nlm.nih.gov/pubmed/24647563 


\title{
Occupational lifting during pregnancy and child's birth size in a large cohort study
}

\author{
by Mette Juhl, PhD, 1, 2 Pernille Stemann Larsen, MSc, ${ }^{2}$ Per Kragh Andersen, DrMedSci, ${ }^{3}$ Susanne Wulff \\ Svendsen, PhD, ${ }^{4}$ Jens Peter Bonde, DrMedSci, ${ }^{5}$ Anne-Marie Nybo Andersen, PhD, ${ }^{2}$ Katrine Strandberg- \\ Larsen, $P h D^{2}$
}

\begin{abstract}
Juhl M, Larsen PS, Andersen PK, Svendsen SW, Bonde JP, Nybo Andersen A-M, Strandberg-Larsen K. Occupational lifting during pregnancy and child's birth size in a large cohort study. Scand J Work Environ Health. 2014;40(4):411-419. doi:10.5271/sjweh.3422
\end{abstract}

\begin{abstract}
Objectives It has been suggested that the handling of heavy loads during pregnancy is associated with impaired fetal growth. We examined the association between quantity and frequency of maternal occupational lifting and the child's size at birth, measured by weight, length, ponderal index, small-for-gestational-age (SGA), abdominal circumference, head circumference, and placental weight.
\end{abstract}

Methods We analyzed birth size from the Danish Medical Birth Registry of 66693 live-born children in the
Danish National Birth Cohort according to the mother's self-reported information on occupational lifting from
telephone interviews around gestational week 16. Data were collected in the period 1996-2002. We used linear
and logistic regression models and adjusted for confounders.

Results In the fully adjusted models, most of the mean differences in birth size measures had values indicating a smaller size of offspring among women with occupational lifting versus women with no lifting, but the differences were very small, and there was a statistically significant trend only for placental weight showing lighter weight with increasing number of kilos lifted per day. In jobs likely to include person-lifting, we found increased odds of SGA among children of women who lifted 501-1000 kilos per day [odds ratio (OR) 1.34,95\% confidence interval (95\% CI) $0.98-1.83$ ] and $>1000$ kilos per day (OR 1.51, 95\% CI 0.83-2.76) compared to no lifting. In jobs with no person-lifting, occupational lifting was not associated with SGA.

Conclusions Overall, we observed no strong support for an association between maternal occupational lifting and impaired size at birth. Our data indicated a potential association between lifting and SGA among offspring of women in occupations that are likely to include person-lifting. These results should, however, be interpreted with caution due to limited statistical power, and we suggest that future studies include detailed, individual information on job functions and ergonomic routines of lifting procedures.

Key terms antenatal guideline; birth weight; fetal growth; offspring; work environment.

Even though physically strenuous work is generally discouraged during pregnancy, handling of heavy loads at work is not unusual among pregnant women even in a well-regulated welfare state like Denmark. In the Danish National Birth Cohort (DNBC), 12\% of all occupationally active women lifted single loads $>20$ kilos on a daily basis at work in the first part of their pregnancy, and 13\% lifted $>100$ kilos a day $(\mathrm{N}=71500)(1)$. These propor- tions are probably even lower than what is expected for the source population due to a selection of better-off women into the cohort (2). We have recently shown that women with heavy occupational lifting in the DNBC had higher risk of miscarriage and preterm birth than women with no lifting $(1,3)$. Work that involves heavy lifting has also been suggested to affect the growth of the fetus (4-10). Reassignment of pregnant women to a

1 The Research Unit Women's and Children's Health, The Juliane Marie Centre, Copenhagen University Hospital, Rigshospitalet, Denmark.

2 Section of Social Medicine, Department of Public Health, University of Copenhagen, Denmark.

3 Section of Biostatistics, Department of Public Health, University of Copenhagen, Denmark.

4 Danish Ramazzini Centre, Department of Occupational Medicine, Herning Regional Hospital, Denmark.

5 Department of Occupational and Environmental Medicine, Bispebjerg Hospital, Denmark.

Correspondence to: Mette Juhl, The Research Unit Women's and Children's Health, The Juliane Marie Centre, Rigshospitalet, Dep.7821, DK - 2100 Copenhagen Ø, Denmark. [E-mail: metjuhl@gmail.com] 
safer job and/or preventive withdrawal from work has been found to reduce the risk of small-for-gestationalage (SGA) among the offspring of women exposed to occupational lifting (11).

During physical exertion, the maternal blood flow is redirected away from the uterine area in order to supply the muscles. This results in an acute reduction in the maternal-fetal blood flow, and occupational biomechanical working exposures (such as predominant standing position, frequent bending, or heavy lifting) may increase the duration of such periods and, thus, potentially cause a restriction of fetal nutritional supplies (12-15). Fetal growth is an indicator of both fetal health and health later in life (16-21), and regular occupational lifting is one of the least documented ergonomic occupational exposures in relation to fetal growth (22).

Recently, a median overall relative risk (RR) for SGA of 1.08 [inter quartile range (IQR) 1.04-1.17] was reported among children of women with occupational lifting (23). In most other studies, lifting was included as part of a broader measure of physical workload, which makes it difficult to identify potential isolated effects of lifting and compare results. Hence, heavy physical work was associated with SGA in a meta-analysis from 2000 [odds ratio (OR) 1.39, 95\% confidence interval $(95 \%$ CI) 1.31-1.46] (7), and a recent review reported a small increased risk of SGA among the children of women with physically strenuous work (24). The latter study, however, provided sparse evidence on this specific question.

Most often, a dichotomized measure of birth weight has been analyzed (ie, low birth weight or SGA) but since fetal growth can be impaired also within normal ranges of birth weight, there is a need for analyses of continuous birth weight. Also, only a few studies have included birth size measures other than birth weight. In the Southampton Women's Survey maternal lifting in the first trimester was associated with small head circumference (OR 1.64, 95\% CI 0.96-2.81), while no association was found with abdominal circumference (25). Growth indicators, such as head and abdominal circumference, seem to act as independent health predictors $(21,26-29)$ and are essential parameters if asymmetrical growth retardation is to be detected $(21,30,31)$.

The shortage of studies that target occupational lifting and fetal growth and the shortcomings of existing literature may cause uncertainty among expecting parents, employers, and health professionals. Due to lack of evidence, no maximum limits on weight load or lifting frequency are given in the Danish Work Environment Guidelines, and in the recommendations lifting is included in a broader measure of physical strain (32). Up to 2009 , it was specified that pregnant women should not carry single loads $>12$ kilos and $\leq 1000$ kilos in total during a work day (33).
We used data from the DNBC to examine the association between maternal occupational lifting and birth size in the offspring, measured by weight, length, ponderal index, SGA, abdominal circumference, head circumference, and placental weight. We analyzed the frequency of lifting 11-20 kilos and $>20$ kilos a day, and the total quantity of kilos lifted per day.

\section{Methods}

The DNBC is a population-based pregnancy cohort with longitudinal follow-up of the children.

Pregnant women in Denmark were recruited at the first antenatal visit to the general practitioner or the midwife. The intention during recruitment (1996-2002) was to invite as many eligible women as possible until the goal of 100000 pregnancies had been reached; inclusion criteria were defined as (i) Danish residency, (ii) no plans for an induced abortion, and (iii) sufficient fluency in Danish to participate in four telephone interviews during and after pregnancy. Participation required a signed informed consent form. The initial data collection included telephone interviews, questionnaires, and blood samples. The first pregnancy interview used in this study was scheduled to take place during pregnancy weeks $12-16$. The median gestational age for the interview was 16.3 completed gestational weeks (114 days; $10^{\text {th }}$ percentile $=84$ days; $90^{\text {th }}$ percentile $=160$ days). About half of the general practitioners agreed to take part in the recruitment process, and we estimate that about $60 \%$ of the invited women accepted the invitation corresponding to approximately $30 \%$ of the target population. Please refer to www.dnbc.dk and cohort descriptions for additional information $(34,35)$. The Scientific Ethical Committee approved the cohort, and the Danish Data Protection Agency approved storage, handling, and linkage of data for the current study. Among the 100418 pregnancies in the DNBC, first pregnancy interview data were available for 90165 . We restricted data to the 73 479 pregnancies, where the woman worked a minimum of 15 hours per week by the time of the interview or within three months prior to the interview. We excluded pregnancies with the outcomes: (i) mola hydatidosa or ectopic pregnancy $(\mathrm{N}=14)$, (ii) spontaneous abortion ( $\mathrm{N}=685)$, (iii) induced abortion ( $\mathrm{N}=147)$, (iv) a stillborn singleton ( $\mathrm{N}=233)$, (v) multiple pregnancies $(\mathrm{N}=1597)$, and (vi) pregnancies where the woman emigrated or died during pregnancy or with unknown outcome of pregnancy $(\mathrm{N}=32)$. We further excluded pregnancies with missing or incomplete information on gestational age at birth $(\mathrm{N}=34)$, occupational lifting $(\mathrm{N}=1589)$, or any of the other covariates included in the regression models $(\mathrm{N}=2182)$. 
From the remaining 66966 pregnancies, we generated six datasets, each conditioned on complete information on the outcome in question: birth weight/SGA $(\mathrm{N}=66$ 617), birth length $(\mathrm{N}=66161)$, ponderal index $(\mathrm{N}=66$ 146), abdominal circumference $(\mathrm{N}=63$ 726), head circumference $(\mathrm{N}=65$ 146), and placental weight $(\mathrm{N}=64$ 561). Finally, for descriptive analysis, we generated a dataset, where we had complete information on at least one of the following outcome variables: birth weight, length, abdominal circumference, head circumference, or placental weight $(\mathrm{N}=66693)$.

\section{Measurement of occupational lifting}

We used self-reported data on occupational lifting of heavy loads. In the first pregnancy telephone interview the women were asked: (i) "In your job, do you daily lift $>20$ kilos at a time (approximately like a crate of beer)?" (ii) "How many times a day do you lift $>20$ kilos? (if 'yes' to the above)" (iii) "In your job, do you daily lift between 11-20 kilos at a time (less than a crate of beer and more than a bucket of water)?" (iv) "How many times a day do you lift between 11-20 kilos? (if 'yes' to the above)"

A crate of beer is a solid plastic crate holding 30 beers in glass bottles. It weighs about 22 kilos and is a generally well-known item in Denmark. Women who reported "less than once daily" in questions 2 or 4 were regarded as "non-lifters" of the given weight load. In the following, 11-20 kilos is referred to as medium loads, and $>20$ kilos as heavy loads. We combined information on medium and heavy loads with the frequency of daily lifts and calculated the cumulated number of kilos lifted per day $(0-14,15-100,101-200,201-500,501-1000,>1000$ kilos). In this calculation, 11-20 kilo loads were classified as 15 kilos, $>20$ kilo loads as 22.5 kilos, and lifting either of these weight loads $<1 /$ day as $0-14$ kilos (ie, "no lifting"). The women were asked about occupational lifting at the time of the interview and during the three previous months. There may be differences in the character of lifting and the subjective assessment of lifting between person-lifting and lifting of non-living objects; for subanalyses, we stratified our data according to whether the woman had a job title that most likely implied personlifting or not (ie, patients, older people, children etc). The woman's job title was coded by the interviewer according to the Danish International Standard Classification of Occupations (DISCO-88), and we defined job titles with likely person-lifting as nurses, midwives, health visitors, nursery teachers/assistants/aides, hospital porters, and ambulance assistants or paramedics (3).

\section{Measurement of birth size}

By linkage to the Danish Medical Birth Registry we obtained data on offspring size at birth, ie, weight (grams), length (centimeters), abdominal and head circumference (centimeters), and placental weight (grams). We further calculated the ponderal index (weight in grams $\times 100$ divided by length in cubic centimeters) (36) and generated an SGA-variable defined as the sexspecific $10 \%$ lightest babies in each gestational week within the study population.

\section{Covariates}

Maternal age at conception $(<25,25-<35,35-<40$, $\geq 40$ years), gestational age at birth (days), and sex of the offspring came from hospital birth records from the Danish National Discharge Registry. From the first pregnancy interview we had information on parity $(0$, $\geq 1)$, pre-pregnant body mass index $(<18.5,18.5-<25$, $25-<30,30-<35, \geq 35 \mathrm{~kg} / \mathrm{m}^{2}$ ), occupational status determined from the self-reported job titles combined with the reported job situation (higher grade professionals, lower grade professionals, skilled workers, unskilled workers), daily smoking at any time during pregnancy before the interview $(0,1-9, \geq 10$ cigarettes per day), alcohol consumption ( $0,0.5-1.5,2-3.5, \geq 4$ units/week), physical exercise (yes, no), leisure-time daily lifting $>20$ kilos (yes, no), and predominant working posture (standing/walking, sitting, varying). All covariates were selected a priori as potential confounders.

\section{Statistical analysis}

Using linear regression analysis, we estimated crude mean differences in birth weight, length, ponderal index, abdominal circumference, head circumference, and placental weight according to number of kilos lifted per day (5 levels) and daily frequency (3 levels) of lifts $>20$ and 11-20 kilos. Second, we adjusted for gestational age at birth, and third, we included all other covariates. The frequency of lifts $>20$ and 11-20 kilos, respectively, were mutually adjusted. Finally, we calculated the OR of SGA among the offspring according to occupational lifting with further stratification by jobs with and without person-lifting. For the latter, we generated one variable with five levels of kilos lifted per day both for jobs likely and not likely to include person-lifting, respectively, and with non-lifters as the overall reference group. Tests for trend were made using the categorical variables for kilos lifted per day and frequency of heavy and medium lifts. Analyses were carried out in SAS Statistical Software V9.1.3 (SAS Institute, Cary, NC, USA). 


\section{Results}

Table 1 shows maternal characteristics according to occupational lifting in 66693 pregnancies. Compared to non-lifters, women who reported occupational lifting, were slightly younger, more likely to be parous, more often in unskilled jobs and more likely to report standing or walking as the predominant working posture (table 1). Furthermore, they had a slightly higher pre-pregnant body mass index, were less likely to engage in leisure-time physical activity and to report any alcohol consumption, and more likely to report smoking and lifting of heavy objects outside the workplace.

Table 2 shows mean differences in birth weight, length, ponderal index, abdominal and head circumference, and placental weight. In the fully adjusted models most of the mean differences in birth size measures had values indicating smaller size of offspring of women with occupational lifting than women with no lifting, but the differences were very small. Only for placental weight was there a statistically significant test for trend with increasing number of kilos lifted per day (table 2). The mean negative differences in birth weight, length, and placental weight were larger in the second highest category of kilos lifted per day compared to no lifting, but not in the highest category. Also, among those lifting 11-20 kilos $>10$ times a day, the adjusted mean differences in birth weight, length, and placental weight indicated reduced size, which was not the case among those lifting $>20$ kilos $>10$ times a day.

We used a dichotomized measure, SGA, as an alternative approach to calculating mean differences in birth size. We found no association between maternal occupational lifting and SGA in the offspring, neither

Table 1. Maternal characteristics according to occupational heavy lifting during pregnancy. The Danish National Birth Cohort $1996-2002$. $\mathrm{N}=666$ 693. [BMl=body mass index; $\mathrm{SD}=$ standard deviation]

\begin{tabular}{|c|c|c|c|c|c|c|c|c|c|c|c|c|c|c|c|c|c|c|c|c|c|}
\hline & \multicolumn{21}{|c|}{ Kilos lifted/day } \\
\hline & \multicolumn{3}{|c|}{$\begin{array}{c}\text { Total } \\
(\mathrm{N}=66693)\end{array}$} & \multicolumn{3}{|c|}{$\begin{array}{c}0-14 \text { a } \\
(\mathrm{N}=49221)\end{array}$} & \multicolumn{3}{|c|}{$\begin{array}{c}15-100 \\
(N=9165)\end{array}$} & \multicolumn{3}{|c|}{$\begin{array}{l}101-200 \\
(\mathrm{~N}=3542)\end{array}$} & \multicolumn{3}{|c|}{$\begin{array}{l}201-500 \\
(N=3196)\end{array}$} & \multicolumn{3}{|c|}{$\begin{array}{l}501-1000 \\
(N=1071)\end{array}$} & \multicolumn{3}{|c|}{$\begin{array}{l}>1000 \\
(\mathrm{~N}=498)\end{array}$} \\
\hline & Mean & SD & $\%$ & Mean & SD & $\%$ & Mean & SD & $\%$ & Mean & SD & $\%$ & Mean & SD & $\%$ & Mean & SD & $\%$ & Mean & SD & $\%$ \\
\hline Age at conception & 29.5 & 4.2 & & 29.8 & 4.1 & & 28.7 & 4.3 & & 28.7 & 4.3 & & 28.8 & 4.4 & & 28.5 & 4.4 & & 28.3 & 4.5 & \\
\hline Pre-pregnancy BMI & 23.5 & 4.2 & & 23.3 & 4.0 & & 23.9 & 4.4 & & 24.2 & 4.6 & & 24.5 & 4.9 & & 24.9 & 5.1 & & 24.8 & 4.8 & \\
\hline $\begin{array}{l}\text { Parity (nullipara) } \\
\text { Occupational status }\end{array}$ & & & 48 & & & 49 & & & 48 & & & 42 & & & 39 & & & 38 & & & 37 \\
\hline $\begin{array}{l}\text { Higher grade } \\
\text { professionals }\end{array}$ & & & 11 & & & 14 & & & 3 & & & 2 & & & 2 & & & 2 & & & 4 \\
\hline $\begin{array}{l}\text { Lower grade } \\
\text { professionals }\end{array}$ & & & 33 & & & 33 & & & 38 & & & 34 & & & 29 & & & 23 & & & 12 \\
\hline Skilled workers & & & 22 & & & 27 & & & 10 & & & 8 & & & 7 & & & 9 & & & 11 \\
\hline Unskilled workers & & & 28 & & & 20 & & & 43 & & & 51 & & & 57 & & & 63 & & & 70 \\
\hline Students & & & 6 & & & 6 & & & 6 & & & 5 & & & 5 & & & 4 & & & 4 \\
\hline $\begin{array}{l}\text { Exposures during } \\
\text { pregnancy } \\
\text { Smoking } \\
\text { (cigarettes/day) }\end{array}$ & & & & & & & & & & & & & & & & & & & & & \\
\hline 0 & & & 76 & & & 78 & & & 72 & & & 69 & & & 65 & & & 61 & & & 58 \\
\hline $1-10$ & & & 19 & & & 17 & & & 21 & & & 23 & & & 25 & & & 26 & & & 27 \\
\hline$>10$ & & & 5.4 & & & 4 & & & 7 & & & 8 & & & 10 & & & 13 & & & 15 \\
\hline $\begin{array}{l}\text { Alcohol consump- } \\
\text { tion (units/week) }\end{array}$ & & & & & & & & & & & & & & & & & & & & & \\
\hline 0 & & & 54 & & & 52 & & & 56 & & & 58 & & & 61 & & & 60 & & & 63 \\
\hline $0.5-1.5$ & & & 34 & & & 35 & & & 33 & & & 30 & & & 28 & & & 30 & & & 28 \\
\hline $2-3.5$ & & & 10 & & & 11 & & & 9 & & & 9 & & & 9 & & & 9 & & & 6 \\
\hline$\geq 4$ & & & 2.2 & & & 2.2 & & & 2 & & & 2 & & & 2 & & & 2 & & & 3 \\
\hline $\begin{array}{l}\text { Physical exercise } \\
\text { (yes) }\end{array}$ & & & 37 & & & 38 & & & 37 & & & 33 & & & 32 & & & 30 & & & 29 \\
\hline $\begin{array}{l}\text { Leisure-time daily } \\
\text { lifting of } \\
\text { objects }>20 \text { kilos } \\
\text { Predominant } \\
\text { working posture }\end{array}$ & & & 6.6 & & & 5 & & & 9 & & & 10 & & & 12 & & & 13 & & & 13 \\
\hline Sitting & & & 25 & & & 33 & & & 4 & & & 2 & & & 1 & & & 1 & & & 1 \\
\hline Varying & & & 48 & & & 49 & & & 47 & & & 40 & & & 41 & & & 30 & & & 23 \\
\hline Walking/standing & & & 27 & & & 18 & & & 49 & & & 58 & & & 57 & & & 69 & & & 76 \\
\hline
\end{tabular}

a There is no total zero-category for methodological reasons. Please refer to methods section in paper. 
Table 2. Mean differences in birth weight, length, Ponderal Index, abdominal and head circumference, and placental weight according to occupational heavy lifting during pregnancy. The Danish National Birth Cohort 1996-2002. N varies according to outcome. [95\% Cl=95\% confidence interva $0.0845 \mathrm{I}]$

\begin{tabular}{|c|c|c|c|c|c|c|c|c|c|c|}
\hline & \multicolumn{5}{|c|}{$\begin{array}{c}\text { Birth weight, g } \\
(\mathrm{N}=66617)(\text { mean }=3589)\end{array}$} & \multicolumn{5}{|c|}{$\begin{array}{c}\text { Birth length, } \mathrm{cm} \\
(\mathrm{N}=66 \text { 161) }(\text { mean }=52.3)\end{array}$} \\
\hline & Crude & Adjusteda & Adjusted $^{b}$ & $95 \% \mathrm{Cl}$ & $\begin{array}{l}\text { P-value for } \\
\text { trend }\end{array}$ & Crude & Adjusteda & Adjusted ${ }^{b}$ & $95 \% \mathrm{Cl}$ & $\begin{array}{l}\text { P-value for } \\
\text { trend }\end{array}$ \\
\hline Kilos lifted per day & & & & & 0.0991 & & & & & 0.0845 \\
\hline $0-14^{c}$ & 0 & 0 & 0 & .. & & 0 & 0 & 0 & & .. \\
\hline $15-100$ & -2 & -1 & -2 & $-13-7$ & & -0.06 & -0.05 & -0.007 & $-0.06-0.04$ & \\
\hline $101-200$ & -14 & -3 & -14 & $-30-2$ & & -0.17 & -0.12 & -0.09 & $-0.16--0.01$ & \\
\hline $201-500$ & -13 & 2 & -11 & $-28-5$ & & -0.13 & -0.08 & -0.04 & $-0.12-0.04$ & \\
\hline $501-1000$ & -32 & -21 & -33 & $-60--5$ & & -0.27 & -0.22 & -0.16 & $-0.29--0.02$ & \\
\hline$>1000$ & -35 & 17 & 7 & $-33-47$ & & -0.36 & -0.11 & -0.03 & $-0.22-0.15$ & \\
\hline \multicolumn{11}{|c|}{ Lifts per day $(>20 \mathrm{~kg})^{\mathrm{d}}$} \\
\hline 0 & 0 & 0 & 0 & .. & & 0 & 0 & 0 & & .. \\
\hline $1-10$ & -6 & -1 & -2 & $-15-11$ & & -0.10 & -0.09 & -0.02 & $-0.09-0.04$ & \\
\hline$>10$ & -52 & -11 & -2 & $-31-27$ & & -0.38 & -0.17 & -0.03 & $-017-0.11$ & \\
\hline \multicolumn{11}{|c|}{ Lifts per day $(11-20 \mathrm{~kg})^{\mathrm{d}}$} \\
\hline 0 & 0 & 0 & 0 & .. & & 0 & 0 & 0 & & .. \\
\hline $1-10$ & -6 & 0 & -4 & $-14-7$ & & -0.08 & -0.06 & -0.007 & $-0.06-0.04$ & \\
\hline \multirow[t]{3}{*}{$>10$} & -28 & -9 & -23 & $-43--3$ & & -0.23 & -0.15 & -0.10 & $-0.19--0.003$ & \\
\hline & \multicolumn{5}{|c|}{$\begin{array}{l}\text { Ponderal Index, } \mathrm{g} \times 100 / \mathrm{cm}^{3} \\
(\mathrm{~N}=66,617)(\mathrm{mean}=2.5)\end{array}$} & \multicolumn{5}{|c|}{$\begin{array}{l}\text { Abdominal circumference, } \mathrm{cm} \\
(\mathrm{N}=63,726)(\text { mean }=33.5)\end{array}$} \\
\hline & Crude & Adjusteda $^{a}$ & Adjusted $^{b}$ & $95 \% \mathrm{Cl}$ & $\begin{array}{l}\text { P-value for } \\
\text { trend }\end{array}$ & Crude & Adjusteda & Adjusted $^{b}$ & $95 \% \mathrm{Cl}$ & $\begin{array}{l}\text { P-value for } \\
\text { trend }\end{array}$ \\
\hline Kilos lifted per day & & & & & 0.6239 & & & & & 0.1283 \\
\hline $0-14^{c}$ & 0 & 0 & 0 & .. & & 0 & 0 & 0 & .. & \\
\hline $15-100$ & 0.01 & 0.01 & -0.0008 & $-0.008-0.006$ & & -0.03 & -0.02 & -0.03 & $-0.09-0.02$ & \\
\hline $101-200$ & 0.01 & 0.01 & 0.0002 & $-0.01-0.01$ & & -0.03 & 0.006 & -0.05 & $-0.12-0.03$ & \\
\hline $201-500$ & 0.01 & 0.01 & -0.006 & $-0.02-0.005$ & & 0.03 & 0.07 & -0.003 & $-0.08-0.08$ & \\
\hline $501-1000$ & 0.01 & 0.01 & -0.002 & $-0.02-0.02$ & & -0.02 & 0.01 & -0.06 & $-0.19-0.07$ & \\
\hline$>1000$ & 0.02 & 0.02 & -0.005 & $-0.02-0.03$ & & -0.09 & 0.08 & -0.02 & $-0.17-0.21$ & \\
\hline \multicolumn{11}{|l|}{ Lifts per day $(>20 \mathrm{~kg})^{\mathrm{d}}$} \\
\hline 0 & 0 & 0 & 0 & .. & & 0 & 0 & 0 & .. & \\
\hline $1-10$ & 0.009 & 0.01 & 0.002 & $-0.007-0.01$ & & -0.0009 & 0.02 & 0.007 & $-0.06-0.07$ & \\
\hline$>10$ & 0.004 & 0.009 & -0.003 & $-0.02-0.02$ & & -0.14 & -0.02 & -0.05 & $-0.19-0.09$ & \\
\hline \multicolumn{11}{|c|}{ Lifts per day $(11-20 \mathrm{~kg})^{\mathrm{d}}$} \\
\hline 0 & 0 & 0 & 0 & .. & & 0 & 0 & 0 & .. & \\
\hline $1-10$ & 0.007 & 0.007 & -0.002 & $-0.009-0.004$ & & -0.02 & -0.0001 & -0.03 & $-0.08-0.02$ & \\
\hline$>10$ & 0.01 & 0.01 & -0.003 & $-0.02-0.01$ & & -0.03 & 0.03 & -0.03 & $-0.13-0.06$ & \\
\hline
\end{tabular}

Head circumference, $\mathrm{cm}$ $(\mathrm{N}=65,146)($ mean $=35.3)$
Placental weight, $g$ $(\mathrm{N}=64,561)($ mean $=663)$

\begin{tabular}{|c|c|c|c|c|c|c|c|c|c|c|}
\hline & Crude & Adjusteda & Adjusted $^{b}$ & $95 \% \mathrm{Cl}$ & $\begin{array}{l}\text { P-value for } \\
\text { trend }\end{array}$ & Crude & Adjusteda & Adjusted ${ }^{b}$ & $95 \% \mathrm{Cl}$ & $\begin{array}{l}\text { P-value for } \\
\text { trend }\end{array}$ \\
\hline Kilos lifted per day & & & & & 0.1458 & & & & & 0.0303 \\
\hline $0-14^{c}$ & 0 & 0 & 0 & .. & & 0 & 0 & 0 &.. & \\
\hline $15-100$ & -0.03 & -0.03 & -0.01 & $-0.05-0.02$ & & 1 & 1 & -2 & $-5-2$ & \\
\hline $101-200$ & -0.08 & -0.05 & -0.06 & $-0.11-0.001$ & & 1 & 2 & -4 & $-9-1$ & \\
\hline $201-500$ & -0.03 & -0.009 & -0.02 & $-0.08-0.04$ & & 1 & 2 & -5 & $-10-0$ & \\
\hline $501-1000$ & -0.05 & -0.01 & -0.02 & $-0.12-0.08$ & & -2 & -1 & -10 & $-19--1$ & \\
\hline$>1000$ & -0.11 & 0.03 & 0.02 & $-0.12-0.16$ & & 1 & 6 & -3 & $-17-10$ & \\
\hline \multicolumn{11}{|c|}{ Lifts per day $(>20 \mathrm{~kg})^{\mathrm{d}}$} \\
\hline 0 & 0 & 0 & 0 & .. & & 0 & 0 & 0 &.. & \\
\hline $1-10$ & -0.04 & -0.02 & -0.007 & $-0.06-0.04$ & & 1 & 1 & -1 & $-6-3$ & \\
\hline$>10$ & -0.1 & -0.007 & 0.03 & $-0.08-0.13$ & & 2 & 6 & 4 & $-6-13$ & \\
\hline \multicolumn{11}{|c|}{ Lifts per day $(11-20 \mathrm{~kg})^{\mathrm{d}}$} \\
\hline 0 & 0 & 0 & 0 & .. & & 0 & 0 & 0 &.. & \\
\hline $1-10$ & -0.03 & -0.02 & -0.01 & $-0.05-0.03$ & & 1 & 1 & -2 & $-5-1$ & \\
\hline$>10$ & -0.07 & -0.03 & -0.05 & $-0.12-0.02$ & & -2 & 0 & -9 & $-15--2$ & \\
\hline
\end{tabular}

adjusted for gestational age.

${ }^{b}$ Further adjusted for age at conception, parity, pre-pregnant body mass index, occupational status, and, in pregnancy: smoking, alcohol consumption, physical exercise, leisure time lifting, and predominant working posture.

c There is no total zero-category for methodological reasons. Please refer to methods section of paper.

d Lifting frequency $(11-20 \mathrm{~kg}$ and $>20 \mathrm{~kg}$ ) were mutually adjusted in the fully adjusted models. 
Table 3. Odds ratios (OR) for small-for-gestational-age (SGA) according to occupational heavy lifting during pregnancy. The Danish National Birth Cohort 1996-2002. ( $\mathrm{N}=66617$ ). [95\% Cl=95\% confidence interval].

\begin{tabular}{|c|c|c|c|c|c|}
\hline & Total & $\mathrm{OR}_{\text {crude }}$ & $O R_{a d j}^{b}$ & $95 \% \mathrm{Cl}$ & $\begin{array}{c}\text { P-value for } \\
\text { trend }\end{array}$ \\
\hline Kilos lifted/day & & & & & 0.5697 \\
\hline $0-14 c$ & 49169 & 1.00 & 1.00 & .. & \\
\hline $15-100$ & 9155 & 1.01 & 0.99 & $0.91-1.07$ & \\
\hline $101-200$ & 3539 & 1.08 & 1.08 & $0.96-1.21$ & \\
\hline $201-500$ & 3187 & 1.04 & 1.02 & $0.90-1.16$ & \\
\hline $501-1000$ & 1070 & 1.16 & 1.13 & $0.92-1.38$ & \\
\hline$>1000$ & 497 & 1.14 & 1.09 & $0.81-1.46$ & \\
\hline Lifts/day $(>20 \mathrm{~kg})^{\mathrm{d}}$ & & & & & 0.2725 \\
\hline 0 & 53392 & 1.00 & 1.00 & .. & \\
\hline $1-10$ & 6979 & 0.99 & 0.93 & $0.84-1.03$ & \\
\hline$>10$ & 1246 & 1.19 & 1.04 & $0.84-1.28$ & \\
\hline Lifts/day $(11-20 \mathrm{~kg})^{\mathrm{d}}$ & & & & & 0.3032 \\
\hline 0 & 50186 & 1.00 & 1.00 & .. & \\
\hline $1-10$ & 13549 & 1.02 & 1.03 & $0.95-1.11$ & \\
\hline$>10$ & 2882 & 1.13 & 1.12 & $0.97-1.30$ & \\
\hline
\end{tabular}

a With a $10 \%$ cut-poff oint of an internal reference in the Danish National Birth Cohort.

${ }^{b}$ Adjusted for age at conception, parity, pre-pregnant body mass index, occupational status, and, in pregnancy: smoking, alcohol consumption, physical exercise, leisure-time lifting, and predominant working posture.

c There is no total zero-category for methodological reasons. Please refer to methods section of paper.

d Lifting frequency (11-20 kg and $>20 \mathrm{~kg}$ ) were mutually adjusted in the fully adjusted models.

with the total number of kilos lifted per day nor the number of lifts $>20$ kilos and 11-20 kilos (table 3).

Table 4 shows offspring SGA according to kilos lifted per day among women in jobs that were likely to include person-lifting and jobs that were not likely to do so. In jobs that were likely to include person-lifting, women who lifted $>500$ kilos per day were more likely than non-lifters to give birth to an SGA child, while such an association was not present among women in jobs that were not likely to include person-lifting. When we collapsed the two higher groups into one category $(>500$ kilos per day), the SGA OR were 1.37 (95\% CI 1.04 $1.81)$ for person-lifting and $1.01(95 \%$ CI $0.82-1.24)$ for no person-lifting (data not shown).

\section{Discussion}

In this cohort study of 66693 live-born children of occupationally active women, we observed a tendency toward slightly decreased mean birth size among newborns of women with occupational lifting. The most pronounced reductions were seen for birth weight, length, and placental weight among women in the second highest lifting group (ie, 501-1000 kilos per day) and for frequent daily lifting of objects weighing 11-20 kilos, but the differences were small. When we stratified
Table 4. Small-for-gestational-age (SGA) a according to occupational heavy lifting during pregnancy, stratified by person lifting. The Danish National Birth Cohort 1996-2002. Reference group=no lifting ( $\mathrm{N}=49$ 169). $\mathrm{N}=66$ 617. [OR=0dds ratio; 95\% $\mathrm{Cl}=95 \%$ confidence interval]

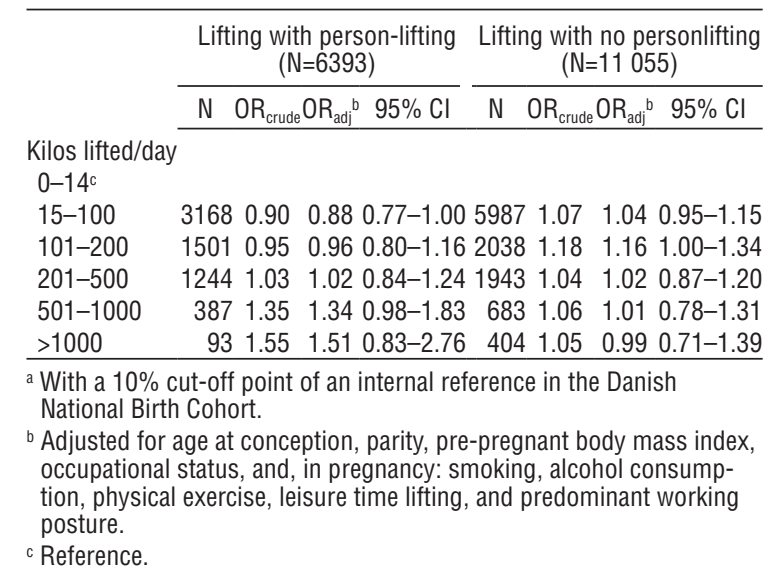

by jobs that were likely/not likely to include personlifting, women who lifted $>500$ kilos per day in jobs that were likely to include person-lifting had increased odds of having an SGA child, but the results lacked statistical power.

Our findings are in line with the more recent overview literature, where either no or only a weak association is suggested between heavy lifting and low birth weight or SGA $(23,24)$. A meta-analysis from 2000 found $40 \%$ increased odds of SGA with physically strenuous work (7). This is not in line with our overall findings but agrees well with the results on heavy lifting in jobs with person-lifting. One reason for the positive findings in the meta-analysis may be that two out of five of the included studies did not have individual data on lifting exposure. Further, manual work includes several aspects of physically strenuous work other than lifting alone, which may explain the positive findings in the included study by Launer and colleagues, who compared women in manual and office work (SGA OR 1.32 , 95\% CI 1.12-1.56) (37). Finally, the largest study in the meta-analysis $(\mathrm{N}=104$ 262) compared offspring SGA of manually working women in occupation units pre-defined as potentially hazardous in pregnancy with those not classified as potentially hazardous; ie, all comparisons were carried out among manually working women and, thus, not immediately comparable with the present study (38).

Our results suggest that person-lifting may imply an increased risk of SGA, even though with limited statistical power. If the perception of lifting differs between occupational groups, this might lead to differential misclassification, if for example certain groups tend to overestimate lifting frequency and weight loads because 
of an awareness of potential hazards related to lifting in pregnancy. This has been suggested for nurses and nursing aids, for example, both of whose jobs usually include person-lifting (39). We used self-reported data on lifting exposure, and, thus, our results may reflect a cultural phenomenon in the reporting of lifting, as suggested above. On the other hand, ergonomic procedures - and thereby physiological mechanisms - differ between lifting of persons and objects, eg, in terms of the leverage of the lifting, lifting techniques, and the use of lifting devices. Our data did not include individual information on what kinds of objects were lifted, or how this was done, and, thus, with regard to person-lifting, we can draw conclusions only on occupations where person-lifting is likely (or not) to be included. Selection into the DNBC in terms of non-participation at enrolment was present in the DNBC; it is likely that women with frequent lifts of heavier loads were less likely to join the study than women with a lighter exposure (or no exposure) to occupational lifting. Such a selection would result in bias if it was also associated with the outcome, but since data were prospectively collected, and the participants did not know about their fetus' growth potential, we do not consider this a serious problem. Further, a method study comparing participants and non-participants in the DNBC indicated that selection into the DNBC is a minor problem with regard to risk factor analyses (2). We may not be able to conclude on very heavy lifting exposures, but since such exposures are relatively rare in pregnancy, our results should apply to a substantial proportion of pregnant women in Denmark. Unfortunately, we did not have data to examine whether non-participation differed between women with occupational lifting versus limited occupational lifting and offspring size at birth. We do not know of generic mechanism creating such bias, but the possibility cannot be ruled out.

This study has several strengths. We had data on lifting exposure on an individual level, and, further, our data enabled the study of more measures of occupational lifting, ie, different weight loads, the frequency of lifting, and the total weight lifted per day. Also, we studied some clinically important outcomes, such as head and abdominal circumference and placental weight, for which there are almost no previous studies according to occupational biomechanical exposures. Thereby we had a theoretical possibility of detecting organ growth differences and asymmetrical growth related to occupational lifting. We used a large population-based pregnancy cohort with prospectively collected exposure data and linkage to national health registries with nearly complete follow-up, and we had access to several background and lifestyle factors for confounder control.

One explanation for our results, including the finding that the most pronounced associations were seen in the second highest lifting group, may be that a number of the women, who reported occupational lifting in the first pregnancy interview, stopped or reduced their lifting later in pregnancy. If there is a causal relation between occupational lifting and fetal growth, such misclassification would attenuate the association, because these women would appear as exposed in our analyses. In Denmark, pregnant women are entitled to paid absence if their work involves a risk to the fetus and referral to suitable alternative work procedures is impossible. Our findings might indicate that these preventive efforts work, in that some of the pregnant women have been removed from heavier lifting tasks at work. Also, confounding or reverse causality may be in play. If pregnancy complications, such as hypertension, bleeding, or uterine contractions, affect the level of occupational lifting, and if such complications lead to impaired fetal growth, this will attenuate an association.

Overall, our data did not clearly indicate impaired fetal growth among the offspring of women with occupational lifting during pregnancy in terms of smaller, average birth size. The largest reductions in offspring size were seen among women in the second highest lifting group and those who lifted medium-heavy objects, which suggests that the preventive recommendations in the Danish Work Environment Guidelines are effective in ensuring pregnant women avoid the heaviest lifting tasks, or that there is a causal relation between occupational lifting over a certain level and decreased birth size, or both. Also, we found a potential association between lifting and offspring SGA among women who worked in occupations that were likely to include person-lifting, but the results had limited statistical power and should be interpreted with caution because the stratification variable was based on the woman's job title. We suggest that future studies collect individual, detailed information about ergonomic procedures in lifting tasks so that the specific ergonomic character of occupational lifting can be studied.

\section{Acknowledgments}

The Danish National Research Foundation has established the Danish Epidemiology Science Centre that initiated and created the Danish National Birth Cohort. The cohort is furthermore a result of a major grant from this Foundation. Additional support for the Danish National Birth Cohort is obtained from the Pharmacy Foundation, the Egmont Foundation, the March of Dimes Birth Defects Foundation, the Augustinus Foundation, and the Health Foundation. The present study was part of the research program MINERVA on working environment and reproduction (www.minervanet. 
$\mathrm{dk}$ ). The MINERVA project was supported by the Danish Working Environment Research Fund (Grant no: 20080016458/4).

The authors declare no conflicts of interest.

\section{References}

1. Juhl M, Strandberg-Larsen K, Larsen PS, Andersen PK, Svendsen SW, Bonde JP, et al. Occupational lifting during pregnancy and risk of fetal death in a large national cohort study. Scand J Work Environ Health. 2013 Jul;39(4):335-42. http://dx.doi.org/10.5271/sjweh.3335.

2. Nohr EA, Frydenberg M, Henriksen TB, Olsen J. Does low participation in cohort studies induce bias? Epidemiology. $2006 \mathrm{Jul} ; 17(4): 413-8$. http://dx.doi.org/10.1097/01. ede.0000220549.14177.60.

3. Runge SB, Pedersen JK, Svendsen SW, Juhl M, Bonde JP, Andersen AM. Occupational lifting of heavy loads and preterm birth: A study within the Danish National Birth Cohort. Occup Environ Med. 2013 Nov;70(11):782-8. http://dx.doi. org/10.1136/oemed-2012-101173.

4. Armstrong BG, Nolin AD, McDonald AD. Work in pregnancy and birth weight for gestational age. Br J Ind Med. 1989 Mar;46(3):196-9.

5. Figa-Talamanca I. Occupational risk factors and reproductive health of women. Occup Med (Lond). 2006 Dec;56(8):521-31. http://dx.doi.org/10.1093/occmed/kq1114.

6. McDonald AD. Work and pregnancy. Br J Ind Med. 1988 Sept;45(9):577-80.

7. Mozurkewich EL, Luke B, Avni M, Wolf FM. Working conditions and adverse pregnancy outcome: A meta-analysis. Obstet Gynecol. 2000 Apr;95(4):623-35. http://dx.doi. org/10.1016/S0029-7844(99)00598-0.

8. Omokhodion FO, Onadeko MO, Roberts OA, Beach JR, Burstyn I, Cherry NM. Paid work, domestic work, and other determinants of pregnancy outcome in Ibadan, southwest Nigeria. Int J Gynaecol Obstet. 2010 Nov;111(2):165-70. http://dx.doi.org/10.1016/j.ijgo.2010.06.016.

9. Saurel-Cubizolles MJ, Kaminski M, Llado-Arkhipoff J, Du MC, Estryn-Behar M, Berthier C, et al. Pregnancy and its outcome among hospital personnel according to occupation and working conditions. J Epidemiol Community Health. 1985 Jun;39(2):129-34. http://dx.doi.org/10.1136/jech.39.2.129.

10. Wergeland E, Strand K, Bordahl PE. Strenuous working conditions and birthweight, Norway 1989. Acta Obstet Gynecol Scand. 1998 Mar;77(3):263-71. http://dx.doi.org/10.1080/ j.1600-0412.1998.770302.x.

11. Croteau A, Marcoux S, Brisson C. Work activity in pregnancy, preventive measures, and the risk of delivering a small-forgestational-age infant. Am J Public Health. 2006;96(5):84655. http://dx.doi.org/10.2105/AJPH.2004.058552.

12. Ahlborg G,Jr. Physical work load and pregnancy outcome. J Occup Environ Med. 1995 Aug;37(8):941-4. http://dx.doi. org/10.1097/00043764-199508000-00009.

13. Clapp JF,III. Pregnancy outcome: Physical activities inside versus outside the workplace. Semin Perinatol. 1996 Feb;20(1):70-6. http://dx.doi.org/10.1016/S01460005(96)80059-0.

14. Florack EI, Zielhuis GA, Pellegrino JE, Rolland R. Occupational physical activity and the occurrence of spontaneous abortion. Int J Epidemiol. 1993 Oct;22(5):87884. http://dx.doi.org/10.1093/ije/22.5.878.

15. Goulet L, Theriault G. Association between spontaneous abortion and ergonomic factors. A literature review of the epidemiologic evidence. Scand J Work Environ Health. 1987 Oct;13(5):399-403. http://dx.doi.org/10.5271/sjweh.2021.

16. Barker DJ, Winter PD, Osmond C, Margetts B, Simmonds SJ. Weight in infancy and death from ischaemic heart disease. Lancet. 1989 Sep 9;2(8663):577-80. http://dx.doi. org/10.1016/S0140-6736(89)90710-1.

17. Eriksson JG, Forsen T, Tuomilehto J, Osmond C, Barker DJ. Early growth and coronary heart disease in later life: Longitudinal study. BMJ. 2001 Apr;322(7292):949-53. http:// dx.doi.org/10.1136/bmj.322.7292.949.

18. Gluckman PD, Hanson MA, Pinal C. The developmental origins of adult disease. Matern Child Nutr. 2005 Jul;1(3):130 41. http://dx.doi.org/10.1111/j.1740-8709.2005.00020.x.

19. Godfrey KM, Barker DJ. Fetal programming and adult health. Public Health Nutr. 2001 Apr;4(2B):611-24. http://dx.doi. org/10.1079/PHN2001145.

20. Leon DA, Lithell HO, Vagero D, Koupilova I, Mohsen R, Berglund L, et al. Reduced fetal growth rate and increased risk of death from ischaemic heart disease: Cohort study of 15000 Swedish men and women born 1915- 29. BMJ. 1998 Jul;317(7153):241-5. http://dx.doi.org/10.1136/ bmj.317.7153.241.

21. Stein CE, Fall CH, Kumaran K, Osmond C, Cox V, Barker DJ. Fetal growth and coronary heart disease in south India. Lancet. 1996 Nov;348(9037):1269-73. http://dx.doi.org/10.1016/ S0140-6736(96)04547-3.

22. Bonzini M, Coggon D, Palmer KT. Risk of prematurity, low birthweight and pre-eclampsia in relation to working hours and physical activities: A systematic review. Occup Environ Med. 2007 Apr;64(4):228-43. http://dx.doi.org/10.1136/ oem.2006.026872.

23. Palmer KT, Bonzini M, Harris EC, Linaker C, Bonde JP. Work activities and risk of prematurity, low birth weight and pre-eclampsia: An updated review with meta-analysis. Occup Environ Med. 2013 Apr;70(4):213-22. http://dx.doi. org/10.1136/oemed-2012-101032.

24. Macdonald LA, Waters TR, Napolitano PG, Goddard DE, Ryan MA, Nielsen P, et al. Clinical guidelines for occupational lifting in pregnancy: Evidence summary and provisional recommendations. Am J Obstet Gynecol. 2013 Aug;209(2):80 8. http://dx.doi.org/10.1016/j.ajog.2013.02.047.

25. Bonzini M, Coggon D, Godfrey K, Inskip H, Crozier S, Palmer KT. Occupational physical activities, working hours and outcome of pregnancy: Findings from the southampton women>s survey. Occup Environ Med. 2009 Oct;66(10):685- 
90. http://dx.doi.org/10.1136/oem.2008.043935.

26. Barker DJ, Shiell AW, Barker ME, Law CM. Growth in utero and blood pressure levels in the next generation. J Hypertens. 2000 Jul;18(7):843-6. http://dx.doi.org/10.1097/00004872200018070-00004.

27. Barker DJ, Osmond C, Simmonds SJ, Wield GA. The relation of small head circumference and thinness at birth to death from cardiovascular disease in adult life. BMJ. 1993 Feb;306(6875):422-6. http://dx.doi.org/10.1136/ bmj.306.6875.422.

28. Phipps K, Barker DJ, Hales CN, Fall CH, Osmond C, Clark PM. Fetal growth and impaired glucose tolerance in men and women. Diabetologia. 1993 Mar;36(3):225-8. http://dx.doi. org/10.1007/BF00399954.

29. Roza SJ, Govaert PP, Vrooman HA, Lequin MH, Hofman A, Steegers EA, et al. Foetal growth determines cerebral ventricular volume in infants the generation $\mathrm{R}$ study. Neuroimage. 2008 Feb;39(4):1491-8. http://dx.doi.org/10.1016/j. neuroimage.2007.11.004.

30. Catalano PM, Thomas AJ, Huston LP, Fung CM. Effect of maternal metabolism on fetal growth and body composition. Diabetes Care. 1998 Aug;21 Suppl 2:B85-90.

31. Stein AD, Zybert PA, van de BM, Lumey LH. Intrauterine famine exposure and body proportions at birth: The Dutch Hunger Winter. Int J Epidemiol. 2004 Aug;33(4):831-6. http://dx.doi.org/10.1093/ije/dyh083.

32. The Danish Working Environment Authority. AT-vejledning. Arbejdsstedets indretning. Gravide og ammendes arbejdsmiljo [Guidelines. The organization of the work place. Work environment for pregnant and breast feeding women]. Copenhagen: The Danish Work Environment Service; 2009.
33. The Danish Working Environment Authority. AT-vejledning. Arbejdsstedets indretning. Gravide og ammendes arbejdsmiljo [Guidelines. The organization of the work place. Work environment for pregnant and breast feeding women]. Copenhagen: The Danish Work Environment Service; 2002. Report No: A1.8.

34. Olsen J, Melbye M, Olsen SF, Sorensen TI, Aaby P, Andersen AM, et al. The Danish National Birth Cohort--its background, structure and aim. Scand J Public Health. 2001 Dec;29(4):300-7. http://dx.doi.org/10.1177/14034948010290040201.

35. Olsen J. Nine months that last a lifetime. Experience from the Danish National Birth Cohort and lessons learned. Int J Hyg Environ Health. 2012 Feb;215(2):142-4. http://dx.doi. org/10.1016/j.ijheh.2011.10.015.

36. Nguyen RH, Wilcox AJ. Terms in reproductive and perinatal epidemiology: 2. Perinatal terms. J Epidemiol Community Health. 2005 Dec;59(12):1019-21. http://dx.doi.org/10.1136/ jech.2004.023465.

37. Launer LJ, Villar J, Kestler E, de OM. The effect of maternal work on fetal growth and duration of pregnancy: A prospective study. Br J Obstet Gynaecol. 1990 Jan;97(1):62-70. http://dx.doi.org/10.1111/j.1471-0528.1990.tb01718.x.

38. Sanjose S, Roman E, Beral V. Low birthweight and preterm delivery, Scotland, 1981-84: Effect of parents> occupation. Lancet. 1991 Aug;338(8764):428-31. http://dx.doi. org/10.1016/0140-6736(91)91045-V.

39. Armstrong BG. Effect of measurement error on epidemiological studies of environmental and occupational exposures. Occup Environ Med. 1998 Oct;55(10):651-6. http://dx.doi. org/10.1136/oem.55.10.651.

Received for publication: 9 September 2013 